\title{
DIREITOS HUMANOS: PERSPECTIVAS, MEDIAÇÕES, PRÁTICAS COMUNICATIVAS - UMA APRESENTAÇÃO
}

\author{
HUMAN RIGHTS: PERSPECTIVES, MEDIATIONS, \\ COMMUNICATIVE PRACTICES - A PRESENTATION
}

\section{Daniel Nascimento e Silva* Daniela Palma**}

\section{PENSAR (DIANTE DE VIOLAÇÕES COTIDIANAS DE DIREITOS HUMANOS)?}

A chamada de artigos para este dossiê "Direitos humanos: perspectivas, mediações, práticas comunicativas" encerrou-se no dia 12 de março de 2018. Dois dias depois, Marielle Franco foi assassinada no Rio de Janeiro. Enquanto os pareceristas liam os manuscritos submetidos, apareciam denúncias de ataques químicos à população síria. Simultaneamente ao nosso trabalho de fechamento deste volume, os jornais estampavam fotos de crianças encarceradas em centros de detenção no Texas, depois da separação forçada de famílias imigrantes pela política de "tolerância zero" do governo Trump.

O contemporâneo não nos permite refletir sobre ele sem sermos tomados de assalto por suas atualizações, o pensamento é invadido pelo torvelinho dos acontecimentos ao nosso redor. No meio da violência que nos ronda - próxima e distante, excepcional e cotidiana -, nosso gesto aqui é o de resistir à sua trivialização - o que há de banalidade na execução de uma vereadora ativista de direitos humanos ou no uso de armas químicas ou em um governo que coloca crianças em jaulas?

A violência desses atos - bem como a banalização que parece estar implícita em sua reiteração quase diária - apontam para o fato de que pensar sobre a capacidade humana de agir socialmente não pode perder de vista "a capacidade humana para o mal", expressão que a filósofa Peg Birmingham (2006, p. 7) emprega para entender uma das preocupações centrais da filosofia política de Hannah Arendt. Para Arendt, a condição para qualquer pensamento político contemporâneo é o reconhecimento de que, assim como a capacidade para a solidariedade, a humanidade tem demonstrado

\footnotetext{
* Universidade Federal de Santa Catarina, Florianópolis (SC), Universidade Federal do Rio de Janeiro, Rio de Janeiro (RJ), Brasil. dnsfortal@gmail.com.

** Universidade Estadual de Campinas (Unicamp), Campinas (SP), Brasil. dpalma@iel.unicamp.br.
} 
uma propensão à violência, ao horror e à destruição. Essa pulsão de aniquilamento, aponta Birmingham, leva Arendt a demandar a formulação de "um novo princípio universal de humanidade" que garanta a "dignidade humana" (BIRMINGHAM, 2006, p. 4). Um exemplo desta demanda pode ser lido no prefácio de Origens do Totalitarismo:

\begin{abstract}
Antissemitismo (e não meramente o ódio aos judeus), imperialismo (não meramente a conquista), totalitarismo (não meramente a ditadura) - um depois do outro, um mais brutalmente que o outro, têm demonstrado que a dignidade humana precisa de uma nova garantia que só pode ser encontrada em um novo princípio político, em uma nova lei na terra, cuja validade desta vez deve compreender o todo da humanidade, ao passo que seu poder deve ser estritamente limitado, assentado e controlado por entidade territoriais diferentemente definidas (ARENDT, 1951, p. xi, tradução nossa).
\end{abstract}

Três anos antes da publicação de Origens do Totalitarismo, em 1948, a então recém-criada ONU publicava a Declaração Universal dos Direitos Humanos, um documento que "tinha como objetivo fazer frente aos horrores praticados contra as vidas humanas pelo mundo" (PASSOS, FACINA, p. 8), particularmente aqueles decorrentes da máquina de guerra nazista que afetara Arendt e outros milhões de judeus. Mas é importante notar que, para Arendt, "o novo princípio político" da humanidade e a "nova lei na terra" não se encerram na mera declaração de direitos universais do ser humano - de fato, direitos do homem e do cidadão já haviam sido proclamados por nações como Alemanha (1525), Inglaterra (1689), França (1789) e Estados Unidos (1791), mas esses documentos não impediram a cristalização do totalitarismo no século XX. Arendt é incisiva ao apontar que essa solidificação gradual do totalitarismo, que resultou na "sociedade do campo de concentração", só foi possível porque "os Direitos do Homem, que nunca tinham sido filosoficamente estabelecidos mas apenas formulados, que nunca tinham sido politicamente assegurados mas meramente proclamados, perderam, em sua forma tradicional, toda validade" (ARENDT, 1951, p. 446).

Como salienta Peg Birmingham (2006, p. 5), Arendt não estabelece uma correlação causal entre as pregressas declarações dos direitos do homem e a "sociedade do campo de concentração", mas busca escavar um espaço subterrâneo em que "o estado nação moderno com sua declaração de direitos humanos está profundamente atrelado [ao] racismo e imperialismo". Para Hannah Arendt, os horrores de que estados-nação e pessoas se mostraram capazes significam uma nova tarefa para a filosofia. Se para os gregos a atividade de pensar vem do afeto da admiração (thauma) - a contemplação da experiência do belo (kalon) que nos arrebata e nos leva a refletir (ver, p.ex., MARTINS, 2011) -, a experiência do totalitarismo e o potencial aniquilador da humanidade, para Arendt, igualmente nos 
arrebatam e nos obrigam a pensar de outra forma. Diz a filósofa que "o horror emudecido diante do que o homem pode fazer e do que o mundo pode se tornar é de várias formas relacionado à admiração emudecida da gratidão a partir da qual as questões da filosofia emergem" (ARENDT, 1954, p. 445).

Assim, a paralisação momentânea diante da violência que tem crescentemente afetado populações vulneráveis ao redor do globo é, desde a chave inicial de Arendt, a nova mola propulsora do pensar. Imbuída da convicção de que, historicamente, preparam-se métodos e condições para que "centenas de milhares de seres humanos [se tornassem] desabrigados, sem Estado, sem lei, e malquistos, enquanto milhões de seres humanos foram feitos economicamente supérfluos e socialmente onerosos pelo desemprego" (ARENDT, 1951, p. 446), Hannah Arendt afirma que assegurar os direitos humanos, e não meramente declará-los, significa pensar sobre uma "nova lei da humanidade" (BIRGMINHAM, 2006, p. 5). Essa nova lei implica uma situação em que cada indivíduo tem o "direito a ter direitos" e, sobretudo, o direito a "pertencer à humanidade" (ARENDT, 1951, p. 298). Já que muitas pessoas, nos anos em que Hannah Arendt viveu e nos anos em que vivemos, foram expropriadas de sua humanidade e consideradas menos que humanas, pensar a condição humana - algo que está para além da natureza biológica humana - é uma tarefa ética por excelência.

\section{PERSPECTIVAS CRÍTICAS NOS DIREITOS HUMANOS}

Neste dossiê, partimos de uma posição a um só tempo crítica e pragmática diante da questão dos direitos humanos. Isso significa entender os direitos humanos, ao mesmo tempo, como ideal universal que assegura o direito a ter direitos a qualquer ser humano (cf. a filosofia de Arendt), e como conceito suscetível a contradições e fissuras em suas instanciações locais - por exemplo, Talal Asad (2003) aponta que os direitos humanos, apesar de universais, dependem, para serem efetivados, de jurisdições de estados-nação, que muitas vezes encontram brechas para violarem esses direitos. Outra fonte de ambivalência dos direitos humanos, que reforçam a necessidade de uma atitude pragmática diante deles, é que pensar sobre os direitos humanos equivale a pensar em uma retórica geralista, positiva, mas imprecisa em sua universalidade; equivale ainda a pensar em figuras de negatividades, as feições sombrias dos enunciados que representam as violações. Contextos singulares, no entanto, constantemente revelam alguns limites da universalidade positiva dos direitos humanos. Limites que Rebecca Saunders aponta no ato de transpor as falas 
do sofrimento de sul-africanos para uma língua padrão dos direitos humanos nos documentos da Comissão da Verdade e Reconciliação:

\begin{abstract}
Ao mesmo tempo em que o emprego pela TRC da linguagem de direitos humanos possibilitou avanços significativos em corrigir registros históricos distorcidos da África do Sul, reconhecendo e documentando graves violações de direitos humanos ocorridas durante o regime de apartheid, atribuindo responsabilidade a certos agentes por tais violações, garantindo dignidade às vítimas e, por vezes, informando-as; o uso desta linguagem também desfigurou o depoimento das vítimas de tal maneira que as afastou de suas próprias experiências (SAUNDERS, 2008, p. 68).
\end{abstract}

Os assentamentos dos ideais universais aos pragmatismos e às singularidades dos contextos da vida humana são o veneno e o remédio da capacidade transformadora dos direitos humanos. Como conciliar princípios humanos universais com especificidades culturais? A proibição do uso do véu em espaços públicos na França representa um movimento em direção à igualdade jurídica dos gêneros pressuposta pelos direitos humanos ou uma violação de uma norma cultural da minoria islâmica no país? O impedimento à transfusão de sangue por testemunhas de Jeová deve ser interpretado como direito à liberdade religiosa ou como violação do direito à vida?

Diante dessas ambivalências, direitos humanos são aqui pensados como corpo discursivo - isto é, como campo de disputas, reivindicações, limites e aspirações. Estrategicamente, populações vulneráveis ao redor do mundo veem nos direitos humanos um terreno de reivindicação de seu direito a ter direitos, sobretudo de seu direito à vida. Pamella Passos \& Adriana Facina (2014, p. 8) comentam que é com "referência [à Declaração Universal dos Direitos Humanos] que ativistas e militantes enfrentam cotidianos de desrespeito e violência em seus países, denunciando internacionalmente as violações cometidas. Como exemplo, podemos citar a denúncia feita à ONU em 2007 por conta das prisões arbitrárias e mortes durante a invasão do Complexo do Alemão, favela da Zona Norte carioca."

As autoras apontam ainda que alguns setores da sociedade têm tentado deslegitimar os direitos humanos; é comum escutarmos no Brasil, por exemplo, os bordões "Direitos humanos são privilégio de bandidos" ou "Direitos humanos para humanos direitos". No entanto, em linha com a filosofia de Hannah Arendt, Passos \& Facina (2014, p. 8) argumentam que "os direitos humanos baseiam-se na premissa de que todas as vidas precisam ser protegidas". Este foi, afinal, o princípio que norteou o trabalho da vereadora Marielle Franco - em toda sua atuação como defensora de direitos humanos, em parceria com o deputado Marcelo Freixo e em seu mandato como vereadora, iniciado em 2017 e tragicamente interrompido em 2018, como favelada e como autora de uma dissertação de mestrado que critica as Unidades de Polícia Pacificadora no Rio de Janeiro como instância de um modelo de 
Estado Penal, que criminaliza a pobreza e, em nome da lei, viola direitos humanos de moradores de favelas (FRANCO, 2014).

O movimento rizomático que emergiu no Brasil e no mundo, em protesto contra o assassinato de Marielle Franco, indica que, mais do que um recurso pragmático de luta contra violações do direito a ter direitos, os direitos humanos são também espaço de imaginação e esperança. "Marielle vive", "Marielle presente", "Marielle é uma semente" são tropos que indiciam o território da utopia e da sobrevivência inscrito nos direitos humanos - algo que desafia os próprios limites da vida orgânica, como atestam esses lemas. Preocupando-se com o fato de que "os direitos humanos tenham se conformado demais à realidade", Moyn (2014, p.136) reivindica justamente a volta da imaginação utópica no delineamento de noções sobre direitos humanos. Esse autor acredita que os direitos humanos talvez tenham se tornado a principal utopia contemporânea; nessa condição, precisariam dialogar e resistir ao mundo que resiste em se transformar. Seu ponto se situaria, assim, entre o utopianismo e o realismo (MOYN, 2014, p. 136).

Esses pontos são vários e na multiplicidade deles se situam os textos que estão reunidos neste dossiê. Os caminhos metodológicos, os diagnósticos, os enquadramentos temáticos e as texturas desses escritos são diversos - alguns deles bem contrastantes entre si. Mas todos eles têm um ponto em comum: alguma aspiração utópica, algo que parece tão grandioso, mas que pode, às vezes, ser traduzido na singeleza da ideia de apenas querer um mundo melhor. A utopia é a constante, o envolvimento com o realismo é presente, mas as formas são singulares e variadas.

A seguir, procedemos a um breve sumário dos artigos que compõem este dossiê.

\section{ENSAIOS SOBRE DIREITOS HUMANOS}

O gesto desnaturalizador e revelador está na escritura de Claudiana Nogueira de Alencar e Daniel Nascimento e Silva que vão buscar o utópico, a esperança, no terreno da brutalidade. Em "Arranjos violentos e esperança: como a linguagem dos direitos humanos operou num atentado em Fortaleza, CE", os autores acionam a escuta de relatos de sobreviventes de um atentado terrorista na Praça da Gentilândia, em Fortaleza (CE), para entender como esses sujeitos responderam à violência do atentado "não por meio de vingança ou de mecanismos extralegais ou excepcionais de violência reativa mas por meio de tropos que informam a defesa dos direitos humanos." A esperança, segundo os autores, pode ser observada não apenas no 
discurso desses sobreviventes, mas também em outras respostas à violência e à violação de direitos humanos no Brasil, como se pode observar nos protestos em resposta ao assassinato de Marielle Franco.

Em "Direitos humanos para quem? Políticas públicas e representação da gestão espacial da pobreza urbana em O Globo", Viviane de Melo Resende, a partir de pressupostos teórico-metodológicos da Análise Crítica do Discurso e da Gramática do Design Visual, analisa 30 matérias do jornal O Globo que tematizam pessoas em situação de rua. Parte de um corpus mais amplo, gerado em projeto de pesquisa da autora que visa "mapear e analisar representações da situação de rua na produção discursiva dos portais de notícias online de três jornais de circulação nacional - Folha de S. Paulo, O Globo e Correio Braziliense", os 30 textos multimodais analisados pela autora recorrentemente enfocam "não o desabrigo, mas a ocupação do espaço público". Dito de outro modo, a disposição enunciativa de recursos textuais e a organização imagética desses textos dão proeminência a privilégios de setores de classe média, ao passo que se distanciam e silenciam direitos da população de rua. A conclusão da autora é que, nesses textos midiatizados, ocupando "a zona do nãoser, a população em situação de rua torna-se corpo manipulável, invisível em sua carência, mas excessivamente visível em sua presença, tomada ora como incômoda ora como perigosa."

O artigo seguinte, "Biopolítica, Direitos Humanos e Resistências: uma Análise Comparativa das Políticas Públicas de Saúde para a População LGBT em Florianópolis-SC", de Atilio Butturi Junior e Camila de Almeida Lara, inscrevese nos estudos do discurso e, em diálogo destes com a antropologia da saúde e a filosofia política, procede a uma análise discursiva de dois documentos que regulam políticas públicas direcionadas à população LGBT na cidade de Florianópolis, SC. Trata-se do I Plano Municipal de Políticas Públicas e Direitos Humanos de Lésbicas, Gays, Bissexuais, Travestis, Transexuais e Transgêneros (PMLGBT I), publicado em 2012, e do II Plano Municipal de Políticas Públicas e Direitos Humanos de Lésbicas, Gays, Bissexuais, Travestis e Transexuais (PMLGBT II), publicado em 2017. A partir de uma discussão sobre a noção de biopolítica em Foucault - isto é, a política que mede, regula e legisla sobre a vida e, assim, produz corpos viáveis -, além da noção de dispositivo da sexualidade, os autores realizam uma crítica da invenção biopolítica de corpos não-heterossexuais nesses dois documentos. Para Butturi e Lara, "o regime de verdade do dispositivo (crônico) da aids (...) marca os corpos LGBT nos documentos, seja de acordo com a captura, seja segundo a possibilidade das resistências." Em sua análise, os autores apontam que, embora esse regime de verdade informe ambos os documentos, diferenças significativas 
podem ser percebidas entre os dois: se por um lado "as propostas pelo PMLGBT I aparecem ancoradas nos discursos do risco e têm como estratégia a prevenção", o PMLGBT II adere a um "discurso interseccional e à positivação da relação entre população LGBT e os discursos de saúde pública". Nesse sentido, o segundo documento permite que se leia a produção de resistências - dinâmicas inscritas no funcionamento do poder para Foucault.

Em "Produção de estórias e o gosto de afazer: exercícios de imaginação em escrita para a educação em direitos humanos", Daniela Palma, Ana Paula dos Santos de Sá, Nayara Natalia de Barros e Rafael Salmazi Sachs elaboram uma proposta de formação de direitos humanos, enfocando a disciplina de Língua Portuguesa, em sua dimensão interdisciplinar. Baseados na filosofia política (e na prática pedagógica) de Hannah Arendt, os autores pensam numa pedagogia dos direitos humanos que contemple a capacidade inventiva e imaginativa da produção de narrativas - o que Hannah Arendt estimulou durante os cursos que ministrou em universidades dos Estados Unidos. Essa produção de estórias, inspirada na prática docente de Arendt, contempla, antes de tudo, a dimensão política do agir educativo e comunicativo no mundo. Trata-se, nas palavras dos autores, de um "como fazer' de natureza política", que se relaciona "diretamente com a busca por formas de pensamento libertário", com a orientação para formas libertárias de linguagem, que abram espaço para o exercício da faculdade de julgar. A produção de estórias em que se realizam esses exercícios também permite o cultivo da sensibilidade vicária de "tocar (imaginativamente) experiências que não são as nossas". Além disso, a prática do "sair em visita" - procurar ler o mundo de outras formas - é também proposta como forma de escuta participativa e dialógica, "possibilitando a transformação das mentalidades e desenvolvimento de um senso comunitário muito mais aguçado." Além dessa proposta inspirada nas aulas de Arendt, os autores mapeiam propostas de educação em direitos humanos nos documentos oficiais do Brasil, bem como propostas da ONU e de países com experiências pioneiras de Comissões de Verdade e Reconciliação, como Argentina e Chile. Esse cuidadoso mapeamento embasa, então, uma proposta de ensino transdisciplinar de língua portuguesa, orientado para a questão dos direitos humanos. Em linha com a proposta crítica e pragmática diante dos direitos humanos deste dossiê, o artigo consiste, assim, numa proposição teórica que, em última instância, demonstra "ser viável a constituição de um caminho bastante específico para o trabalho com direitos humanos em aulas de Língua Portuguesa do Ensino Básico."

Também abordando a questão dos direitos humanos na educação brasileira, o artigo seguinte, "Direitos Humanos e Educação: a polêmica em torno da prova de 
redação do ENEM 2015 e 2017", redigido por Cynthia Agra de Brito Neves, tem como foco específico a proposta do ENEM de fomentar os direitos humanos em sua grade de avaliação. Minuciosamente narrando a polêmica judicial iniciada pelo Escola Sem Partido, que questionou juridicamente a validade do quesito direitos humanos na grade de correção da redação, a autora aponta os diversos atores envolvidos na atual decisão judicial de invalidar um dos critérios fundamentais do ENEM, a saber, a penalização de redações que violem os direitos humanos. Ao entextualizar o termo "mordaça" e ao iterar enunciados de movimentos como Escola Sem Partido e Movimento Brasil Livre, a ministra Carmen Lúcia, uma das protagonistas do cenário de instabilidade que paira sobre o judiciário no Brasil, nitidamente evoca a proposta do Escola Sem Partido, autor da petição inicial que foi endossada em decisão monocrática pela ministra do Supremo. Assim, Cynthia Agra de Brito Neves, por um lado, problematiza a decisão de Carmen Lúcia e o movimento político-ideológico por ela defendido e, por outro lado, aponta os avanços da democracia brasileira no que diz respeito à educação em direitos humanos, analisando detalhadamente documentos que embasam essa proposta. Ao enfatizar algumas iterações de movimentos contrários à educação em direitos humanos em sala de aula - por exemplo, a ameaça anônima que a própria autora recebeu na Unicamp, após ter abordado textos sobre sexualidades LGBT no Programa de Formação Interdisciplinar Superior, fato que gerou nota de repúdio da Congregação do Instituto de Estudos da Linguagem da Unicamp, bem como repercutiu em mídias no Brasil e exterior -, a autora defende que "a Linguística Aplicada $\operatorname{dev}[\mathrm{e}]$ encorajar não apenas um "letramento em direitos humanos" (ABREU, 2015), mas um "letramento ideológico" (STREET, 2014) em direitos humanos."

O artigo seguinte, "El proyecto arqueológico de Foucault y el gobierno por la verdad jurídica. La sede del método arqueológico en los umbrales del campo discursivo", de Paulo Damián Aniceto, realiza uma exegese do projeto arqueológico de Michel Foucault, um autor fundamental para compreender temas centrais da problemática dos direitos humanos, como a vontade de verdade, o dispositivo e a biopolítica. Situado no campo mais amplo dos estudos do discurso, Aniceto realiza um trabalho taquigráfico de leitura do projeto arqueológico de Foucault, do qual gradualmente emerge o caráter histórico e performativo das racionalidades institucionais, que se realizam sobretudo a partir de discursos. $\mathrm{O}$ autor enfatiza a perspectiva ética e política do trabalho foucaultiano, ao mesmo tempo em que propõe uma "abordagem estratégica dos campos discursivos", o que demanda um olhar crítico para a arena de luta em que se constituem os discursos - os quais, "ao mesmo tempo em que dizem a doutrina, competem pelo predomínio de uma verdade e um saber específico, avançando sobre o espaço do não dito."

Em "O Poder do Lógos e sua Dimensão Moral", Laís Lagreca de Carvalho e Ana Paula Grillo El-Jaick revisitam o trabalho dos filósofos sofistas, sobretudo Górgias, autor de Elogio de Helena. Severamente criticados pela filosofia realista 
de Sócrates e Platão, os sofistas foram, no entanto, percussores do pragmatismo no pensamento deles, estão as sementes da ideia de que a linguagem, mais do que dizer o real, age sobre este. Em Górgias principalmente, a linguagem tem um poder demiúrgico: ela opera, produz efeitos no mundo. As autoras articulam, então, o pensamento sofista à proposta moderna de John L. Austin, que inventa a noção de enunciado performativo - aquele enunciado cujo referente é instituído no ato de sua enunciação. Esse pano de fundo demiúrgico-performativo é então contrastado com uma discussão moral sobre a ação na fala contemporânea, em especial com a noção de pós-verdade: se, por um lado, como apontam as autoras, a pós-verdade aponta para o esvaziamento referencial que se dá na significação performativa em contexto de pós-verdade, os referentes são os próprios enunciados, que dizem sua própria "verdade" -, por outro lado, o fenômeno convoca a dimensão moral e perlocucionária do pensamento sobre a performatividade - a discussão passa a ser menos a "exatidão" da verdade (que, obviamente, será sempre objeto de disputa) e mais as consequências e a ética do dizer. Empiricamente, as autoras se apoiam num caso fatal, em que Fabiane Maria de Jesus foi espancada até a morte em Guarujá, no litoral de São Paulo, por ter tido sua imagem associada a uma mulher suspeita de sequestrar crianças. Inocente, Fabiane de Jesus foi morta também pelas tramas morais em que a performatividade - e a irresponsabilidade amplificada pelas mídias digitais - pode se enveredar. Tendo em vista o potencial destrutivo que mídias digitais têm de disseminação de pós-verdades, pensar as implicações de questões de linguagem para a preservação da vida mostra-se como uma grande questão para os direitos humanos.

Pensar a violência nos enquadramentos delineados em processos de produção de sentidos e subjetividades é a proposta do ensaio "Do visível ao nomeado: enquadramento do humano", de Lauro Baldini e Tyara Veriato Chaves. Enquadrar, ato constitutivo da elaboração de discursos nas linguagens das imagens, ganha dimensão política com Butler, que usa o termo (frame, to be framed) para pensar a produção normativa de ontologias que criam "o problema epistemológico de apreender uma vida, o que, por sua vez, dá origem ao problema ético de definir o que é reconhecer ou, na realidade, proteger contra a violação e a violência" (BUTLER, 2015, p. 16). No fio dessa ética, que também funcionaria como um esqueleto do corpo discursivo sobre os direitos humanos, o texto toma a vadiagem - a tipificação de uma contravenção penal, com longo histórico jurídico e político no Brasil - como emolduramento das discursividades de Estado para operar formas de violência que ecoam fantasmas da brutalidade da escravidão e da opressão contra as mulheres. Em um caminho muito singular nas searas da Análise do Discurso, os autores apontam 
para os tensionamentos de sentidos provocados pela apropriação do termo pelo movimento da Marcha das Vadias, uma derivação do canadense SlutWalk que, em confluência com questões históricas locais, tem sua potência significativa amplificada. Ainda voltam seus olhares para algumas imagens de manifestações do movimento, refletindo sobre o enquadramento das fotografias como elemento que "revelava uma espécie de denúncia muda atravessada pela dissimetria entre os corpos dos que militavam e dos que permaneciam nas ruas". Essas análises discursivas ganham também textura psicanalítica, abrindo possibilidades de pensar a articulação entre a condição de desamparo e as capacidades de mobilizar para a ação política.

A discussão sobre a mediação na produção literária de autores subalternizados é o tema do artigo de Lua Gill da Cruz, "A mediação diante do cárcere: os casos de sobrevivente André Du Rap e Cela Forte Mulher". As políticas de reinscrição, um dos núcleos para a compreensão dos direitos humanos, principalmente nas feições mais contemporâneas, apoiam-se na ideia da diversificação nos sistemas de representação histórica e social e na amplificação dos espaços de enunciação e legitimação cultural. A autora dá densidade a essa discussão ao apontar a questão da mediação editorial frequentemente desempenhada por um "intelectual, branco e da elite que organiza e edita a obra de alguém que testemunha outra vivência, o subalternizado, negro e pobre". A partir da análise do processo de produção dos livros Sobrevivente André du Rap, assinado por André du Rap e Bruno Zeni, e Cela forte mulher, assinado por Antonio Carlos Prado, a dimensão autoral na literatura de cárcere contemporânea é reavaliada, explorando as contradições nos processos de reinscrição a partir do exame da relação entre os intelectuais mediadores e detentos que narram as suas experiências. No entanto, afirma Cruz, apontar essas dinâmicas não significa diminuir "a potência de uma escrita testemunhal", afinal todo relato carrega tanto as marcas do narrado como aquelas que o próprio testemunho, nas palavras de Penna, "não deixa contar". (PENNA, 2003, p. 346)

"Não violência não é o mesmo que pacifismo, para o qual existem muitas palavras. (...) O pacifismo é passivo, mas a não violência é ativa. $\mathrm{O}$ pacifismo é inofensivo e, portanto, mais fácil de aceitar do que a não violência", aponta Kurlansky (2013, p. 17) em seu livro sobre a não violência. Mesmo com a distinção conceitual, na língua contemporânea dos direitos humanos, disseminou-se o uso terminológico de "cultura da paz" e "não violência", muitas vezes, como sinônimos, em outras, com sentidos complementares, frequentemente, com valoração positiva. Helena Boschi, em seu artigo "Cultura de paz": gênese de uma fórmula entre discursos de guerra e violência", empreende um rastreamento dos usos do sintagma "cultura da paz" no Brasil, durante cerca de dez anos a partir da instituição da "Década 
Internacional de uma Cultura de Paz e não Violência para as Crianças do Mundo" (ONU, 2001-2010). O estudo utiliza uma armação teórico-metodológica baseada em Krieg-Planque, propondo descrever um funcionamento de "cultura da paz" como fórmula discursiva. A autora mostra como opera a produção de "um efeito de consenso na superfície linguística de um sintagma que, ao circular, é convocado por interpretações diversas que partem majoritariamente do sema central 'convivência'". Esse efeito de consenso atua, por meio da linguagem institucional, na ideia de apaziguamento ou de "apagamento de conflitos políticos", a partir disso, o texto pontua algumas implicações dessa fala neutralizada nas políticas públicas como na "inserção da disciplina "cultura de paz" nos ensinos fundamental e médio, as atividades práticas de "tolerância" e "convivência" (...) até o campo da "segurança pública", em seus mais distintos desdobramentos."

Em "Da hospitalidade à intolerância ao migrante árabe: construções discursivas sobre um mesmo Brasil", Daniele dos Santos de Souza \& Fernando ZolinVesz, a partir de um trabalho indisciplinar (MOITA LOPES, 2006) em Linguística Aplicada, realizam uma análise dos problemas da hospitalidade e hostilidade a imigrantes árabes no Rio de Janeiro. Analisando reportagem publicada no portal G1 sobre um 'esfihaço' realizado por moradores de Copacabana após a agressão sofrida pelo refugiado sírio Mohamed Ali, os autores demonstram que o espaço textual da matéria abriga tanto enunciados de hospitalidade quanto de hostilidade ao refugiado. Eles concluem que a hostilização e acolhimento ao migrante/refugiado, no Brasil contemporâneo, são "fenômenos que se relacionam, dado que, em constante duelo um contra o outro, tentam se apresentar como mais legítimos ou verdadeiros em um mesmo espaço/tempo, compondo o que nomeamos como dois lados de uma mesma moeda na construção discursiva sobre o Brasil contemporâneo - a um só tempo, o país da hospitalidade e o país da intolerância."

Luciana Salazar Salgado e Jaime Tadeu Oliva, em seu artigo "O mal-estar na comunicação: a violação da opinião pública pelo sistema midiático", discutem a comunicação social nas democracias contemporâneas a partir de três concepções interligadas: intersubjetividade, vontade política e opinião pública. Mobilizam, em termos metodológicos, as noções de sistema e mundo da vida "para expor a tensão condicionante das funções atribuídas e das funções assumidas pelo que costuma ser referido por "mídia" no atual período, em especial na sua relação com a política". No funcionamento do sistema midiático nacional sob o controle empresarial, os autores apontam mecânicas de poder que fragilizam a função comunicava essencial de garantia para a democracia. Apontam debates sobre a regulamentação de mídia, como também analisam interpretações sobre o papel das mensagens jornalísticas em 
um cenário de crise institucional política, sob a concepção de violação da opinião pública. Nessas discussões, o texto situa o sentido de "trocas comunicacionais" como um substrato para a garantia de direitos fundamentais em uma sociedade democrática.

Em "Discurso de ódio e dignidade humana: uma análise da repercussão do resultado da eleição presidencial de 2014", Mariana Jantsch de Souza monta e analisa um corpus de mensagens de cunho ofensivo, veiculadas em mídias diversas, repercutindo o resultado do processo eleitoral brasileiro. A autora busca dar relevo conceitual para a noção de uso corrente "discurso de ódio" a partir de uma base teórica que se situa no campo da Análise de Discurso, ancorada principalmente em Pêcheux. As análises realizadas por Souza apontam para a forma como a polarização política desenhada no quadro geral das mensagens construiu sentidos sobre os direitos fundamentais de acordo com as escolhas eleitorais - naquele contexto, eleitores de Dilma Rousseff não eram reconhecidos cidadãos portadores de direitos, apenas como alvos de desqualificação, execração pública e violência. $\mathrm{O}$ artigo oferece algumas chaves para pensar, para além do contexto estudado, a mecânica recorrente em redes sociais de internet de grandes ofensivas de ataques, em geral virulentos e apoiados em preconceitos sociais de longo histórico, a determinados grupos em contextos específicos.

O artigo "Letramentos de sobrevivência em redes digitais: caminhos possíveis na luta por direitos humanos", de Junot de Oliveira Maia, apresenta uma perspectiva sobre como letramentos de sobrevivência - entendidos como "práticas sociais que, fundamentalmente, testemunham violações de direitos humanos e culturais e que, enunciados, questionam polaridades, contaminam a homogeneidade de iniciativas hegemônicas e, assim, entextualizam histórias contadas e escovadas a contrapelo" podem operar no fortalecimento de redes de solidariedades locais e de participação cidadã, em contextos nos quais o Estado se faz presente sobretudo em sua feição penal e policial. Junot de Oliveira Maia relata, no artigo, sua "etnografia de fronteira", abordagem etnográfica por ele proposta em sua pesquisa de doutorado, empiricamente situada no Complexo do Alemão, na zona norte do Rio de Janeiro. Nesse trabalho, o autor analisou texto, falas e enunciados multimodais em mídias digitais de Mariluce Mariá e Cleber Santos, moradores do grupo de favelas, que militam pelos direitos humanos, a partir de seu ativismo em redes sociais digitais e de sua participação em diferentes esferas da cidade do Rio de Janeiro e de outros espaços no Brasil e exterior. Nesse artigo, o autor enfoca mais especificamente uma entrevista concedida por Cleber Santos e Mariluce Mariá no Museu Nacional ao grupo de pesquisadores coordenado pela professora Adriana Facina e o tuitaço 
\#SOSComplexodoAlemão, organizado pelo casal. Em sua análise das múltiplas escalas e das formas de que se valem os ativistas para projetar texto, fala e imagem, o autor conclui que "o aumento considerável da circulação dos produtos dessas práticas de escrita tem se dado principalmente em função da maneira como as tecnologias digitais conectadas viabilizam o trânsito de um texto por variadas cadeias de entextualização que ampliam chances de rompimentos e rupturas nas escritas que criminalizam os moradores de favelas." Letramentos de sobrevivência, assim, mostram-se como potente recurso de grupos minoritarizados na luta pelos direitos humanos.

Em "A formação do professor de línguas em uma perspectiva de educação intercultural cidadã", Joel Windle aborda um projeto didático por ele desenvolvido com licenciandos/as em Letras-Inglês na UFF, com vistas ao desenvolvimento de perspectivas críticas na educação intercultural e direitos humanos. A partir de uma crítica a alguns impasses entre os discursos universalistas de direitos humanos e a perspectiva "relativista" ou situada dos estudos em linguística aplicada, Windle demonstra como o diálogo intercultural entre seus/suas estudantes e sujeitos situados espacialmente em outras partes do mundo se tornou possível. $\mathrm{O}$ autor aborda ainda o trabalho preparatório para esse diálogo, calcado em uma perspectiva crítica na linguística aplicada, na leitura sobre diretrizes de direitos humanos do MEC/Brasil e em atividade sobre o documentário Human. Emerge do artigo uma perspectiva pós-colonial em torno dos direitos humanos e do ensino da língua inglesa - um caso concreto e possível de implementação de ensino crítico de língua estrangeira no Brasil.

Finalmente, em "Respondendo às balas: segurança pública sob intervenção das palavras", apresenta-se a entrevista que Jacqueline de Oliveira Muniz, professora do Departamento de Segurança Pública da Universidade Federal Fluminense, concedeu a Rosiane Rodrigues de Almeida. Na entrevista, uma bricolagem que uniu transcrições de partes de entrevistas concedidas por Jacqueline Muniz a emissoras de TV e jornais impressos bem como partes inéditas produzidas em interação com Rosiane Rodrigues de Almeida, a antropóloga apresenta uma perspectiva crítica sobre a intervenção federal na segurança pública no Estado do Rio de Janeiro, autorizada por Michel Temer em 16 de fevereiro de 2018. Pautada por longa experiência de pesquisa no campo da segurança pública, a posição de Jacqueline Muniz é a de que a intervenção militar consiste numa "cortina de fumaça, uma teatralidade operacional de alto custo e de baixo rendimento, baixa eficácia e baixo resultado." Em vez da opção por um policiamento eficaz, pautado na inteligência, que respeite os direitos humanos, o governo federal optou por um modelo 
inadequado de segurança, "expondo os objetivos político-eleitoreiros que custam caro e não trazem efeitos positivos à população." Essa entrevista, concedida por uma eminente autoridade no campo dos estudos sobre policiamento e segurança pública, sela assim a contribuição que este dossiê pretende fazer ao pensamento sobre a questão dos direitos humanos na vida contemporânea.

\section{REFERÊNCIAS}

ARENDT, H. (1951). The Origins of Totalitarianism. New York: HBJ.

ARENDT, H. (1954). Concern with Politics in Recent European Thought. In: Essays in Understanding, 1930-1954, Ed. by Jerome Kohn. New York: Schoken Books, p. 429-447.

ASAD, T. (2003). Formations of the secular: Christianity, Islam, Modernity. Stanford: Stanford University Press.

ABREU, R. N. (2015). Exercício da cidadania e direitos humanos: as funções da competência V na redação do ENEM. In. SILVA, L. R. da; FREITAS, R. M. K. (Org.). Linguagem, interação e sociedade: diálogos sobre o ENEM. João Pessoa: Editora do CCTA, pp. 97-108.

BIRMINGHAM，P. (2006). Hannah Arendt \& Human Rights: The Predicament of Responsibility. Bloomington \& Indianapolis: Indiana University Press.

BUTLER, J. (2015). Quadros de guerra: quando a vida é passível de luto?. Tradução de Sérgio Lamarão e Arnaldo Marques da Cunha. Rio de Janeiro: Civilização Brasileira.

FRANCO, M. (2014). UPP - A redução da favela a três letras: uma análise da política de segurança pública do estado do Rio de Janeiro. Dissertação de Mestrado, Niterói, UFF.

KURLANSKY, M. (2011). Não violência: a história de uma ideia perigosa. Tradução de Otacílio Nunes. Rio de Janeiro: Objetiva.

MARTINS, H. (2011). Três caminhos na filosofia da linguagem. In: MUSSALIM, F.; BENTES, A. C. (Org.). Introdução à linguística: fundamentos epistemológicos, volume 3.5. ed. São Paulo: Cortez.

MOYN, S. (2014). Human Rights and the uses of History. London, New York: Verso. 
PASSOS, P.; FACINA, A. (2014). Cultura popular e direitos humanos. Rio de Janeiro: Fundo Brasil de Direitos Humanos, IFRJ, Ocupa Borel \& Revista Vírus Planetário. Disponível em: https://issuu.com/virusplanetario/docs/issuu_cartilha Acesso: 18 jul. 2018.

PENNA, J. C. (2003). Este corpo, esta dor, esta fome: notas sobre o testemunho hispanoamericano. In: SELIGMANN-Silva, Márcio (org.). História, memória, literatura: o testemunho na Era das Catástrofes. Campinas, SP: Editora da Unicamp.

SAUNDERS, R. (2008). Sobre o intraduzível: sofrimento humano, a linguagem de direitos humanos e a CVR da África do Sul. Tradução de Thiago Amparo. SUR - Revista Internacional de Direitos Humanos, ano 5, n. 9, p. 53-75.

STREET, B. (2014). Letramentos sociais: abordagens críticas do letramento no desenvolvimento, na etnografia e na educação. Tradução de Marcos Bagno. São Paulo: Parábola.

Recebido: $18 / 07 / 2018$

Aceito: 20/07/2018 